\title{
ANALISIS PERBEDAAN PENGGUNAAN UMPAN TERHADAP HASIL TANGKPAN LONGLINE DI SELAT SUNDA
}

\author{
Derajat Prasetyo $^{1)}$, Riena F. Telussa ${ }^{2)}$ \\ ${ }^{1,2)}$ Jurusan Pemanfaatan Sumberdaya Perairan, FPIK USNI \\ Jln, Arteri Pondok Indsh No. 11 Jakarta 12240 \\ E-mail: deworng214@gmail.com
}

\begin{abstract}
Indonesia as the largest archipelagic country in the world has about 5.8 million $\mathrm{km}^{2}$ of sea and according to World Resources Institute in 1998 has $91,181 \mathrm{~km}$ of coastline containing fishery and marine resources which has great potential to be the foundation of economic development based on natural resources source. The means to be achieved from the implementation of this research are: 1) Understanding the longline fishing gear technique. 2). Understand the catch with different feeds using the longline catch tool. Research on the analysis of differences in use of bait to longline catches was conducted in May 2017 at KLR. Madidihang 03, in the waters of the Selat Sunda. This catch is obtained with a 30 tail feed and 21 Layang fish feeds for the overall setting. The most catch with Milkfish type bait in the 8th setting is catching 8 Fish Cucut, Because Cucut fish is interested in milkfish. While the location of the fishing line or settingnya almost near the beach so that the catch is produced in the form of Cucut fish.
\end{abstract}

Keywords: Selat Sunda, Longline, Type of Feed Milkfish and Layang fish.

\section{PENDAHULUAN}

Longline merupakan salah satu alat tangkap yang efektif dan khusus ditujukan untuk menangkap ikan tuna, karena konstruksinya mampu menjangkau kedalaman renang (Swimming layer) dan sangat sesuai untuk dioperasikan di perairan ZEE 200 mil. Kegiatan penangkapan banyak terjadi di wilayah pesisir, karena daerah tersebut merupakan wilayah subur dan memiliki kelimpahan sumberdaya tinggi (Nybaken, 1988).

Unit alat tangkap longline terdiri dari kapal yang dirancang khusus alat penangkap dan crew. Kapal-kapal tuna modern saat ini dibagian belakang dari kapal telah dirancang dengan baik, sehingga mudah dioperasikan dalam mengatur alat tangkap. Tuna longline sendiri pada umumnya terdiri dari: pelampung, bendera, tali pelampung, tali utama (main line), tali cabang (branch line), pancing wire leader, dan lain-lain. Antara pelampung dengan pelampung dihubungkan dengan tali pelampung dan tali utama dimana sepanjang tali utama terpasang beberapa tali cabang. Satu rangkaian alat inilah yang disebut dengan satu basket longline jumlah mata pancing pada setiap basket bervariasi.

Umpan merupakan salah satu faktor yang sangat besar pengaruhnya terhadap keberhasilan dalam usaha penangkapan baik masalah jenis umpan, sifat 
umpan maupun cara ikan memakan umpan. Pemilihan jenis umpan yang berbeda memungkinkan adanya hasil tangkapan yang berbeda pula di Selat Sunda.

\section{BAHAN DAN METODE}

Penelitian analisis perbedaan penggunaan umpan terhadap hasil tangkapan longline telah dilaksanakan pada bulan Mei 2017 pada Kapal Latih dan Riset Madidihang 03, di perairan Selat Sunda. Pengumpulan data dilakukan secara langsung di lapangan mengenai pengoperasian longline dan melakukan wawancara langsung dengan Crew kapal. Data yang diperoleh dari penelitian ini bersumber pada data primer dan sekunder.

Metode pengoperasian alat tangkap longline di KLR. Madidihang 03 yaitu persiapan darat dilakukan mulai dari logistik, bahan bakar, sampai persiapan crew, untuk di laut yaitu persiapan operasi penangkapan mulai dari persiapan umpan yang akan digunakan penangkapan, branch line, tali pelampung, pelampung, radio bouy dan bendera. Penurunan alat tangkapan hanya menggunakan 210 pancing atau 30 basket dan didalam satu basket berisi 7 mata pancing, umpan yang digunakan untuk operasi penangkapan menggunakan umpan Ikan Bandeng dan Ikan Layang.

\section{METODE PENELITIAN}

Pengolahan data penelitian dilakukan selama waktu operasi penangkapan ikan, dan analisis data disajikan dalam bentuk deskriptif. Bervariasinya data penelitian, membutuhkan cara penganalisaan yang berbeda-beda. Analisis secara deskriptif dilakukan dengan menggambarkan komposisi hasil tangkapan pada setiap kali setting yang dilakukan. Parameter yang diamati hanya dilakukan satu kali selama penelitian yaitu dengan jenis umpan yang berbeda untuk mengetahui hasil tangkapan yang diperoleh selama lima belas hari.

\section{ANALISIS DATA}

Perbandingan anatara kedua jenis umpan (ikan Layang dan ikan Bandeng) terhadap hasil tangkapan yang digunakan diuji dengan menggunakan analisis statistik Uji $t$-student. Uji $t$-student dimaksudkan untuk dua nilai tengah dan jelas tidak sesuai untuk generalisasi bagi lebih dari dua, karena tidak ada cara yang jelas untuk menentukan suatu pembilang bagi generalisasi tersebut (Steel and Torrie, 1980). Dengan dua jenis umpan yang berbeda sebagai perlakuan dan jumlah setting sebagai ulangan. Analisis statistika mendeskripsikan setiap settingan yang dilakukan sebagai ulangan. Sedangkan mendeskripsikan jenis umpan Bandeng dan Layang sebagai perlakuan. Dengan demikian karena ulangan yang dilakukan kurang dari 10 kali (hanya 8) dan digunakan dua perlakuan saja, maka metode yang mungkin dilakukan adalah metode analisis $t$-student

Penelitian hanya menggunakan dua jenis perlakuan saja dimana dalam hal ini adalah jenis umpan Layang dan Bandeng maka dengan melihat hasil dari pengujian hipotesis melalui analisis $t$-student, telah dapat diketahui jenis umpan apakah yang dapat memberikan hasil tangkapan yang baik. 


\section{HASIL DAN PEMBAHASAN}

Dalam melakukan suatu operasi penangkapan KLR. MADIDIHANG 03 harus melakukan beberapa persiapan sebelum melakukan pengoperasian di daerah Selat Sunda. Persiapan tersebut harus dilakukan dengan baik dan benar baik di darat maupun di laut. KLR. MADIDIHANG 03 melakukan pengoperasian penangkapan dengan menggunakan alat tangkap longline serta menggunakan mata pancing sebanyak 210 buah dan sudah mempersiapkan daerah penangkapan (fishing ground) yang akan melakukan pengoperasian di daerah Selat Sunda.

Selama penelitian ini dilakukan untuk pengoperasian alat tangkap longline dalam 15 hari hanya dilakukan 8 kali setting (4 hari) dengan menggunakan umpan Bandeng dan umpan Layang, dalam satu hari dilakukan dua kali setting yaitu pada pagi dan sore hari, dengan menggunakan kedua jenis umpan, dari umpan Ikan Bandeng dan umpan Ikan Layang selama penelitian didapatkan hasil tangkapan keseluruhan dengan jumlah 51 ekor. Untuk hasilnya dapat dilihat pada Tabel 3.

Tabel 3. Hasil Tangkapan 8 kali Setting Pagi Hari dan Sore Hari

\begin{tabular}{|c|c|c|c|c|}
\hline \multirow{2}{*}{ Setting } & \multicolumn{3}{|c|}{ Jenis Ikan (Ekor) } & \multirow{2}{*}{ Hasil Tangkapan (Ekor) } \\
\cline { 2 - 4 } & Cucut & Meka & Marlin & 7 \\
\hline 1 & 7 & 0 & 0 & 7 \\
\hline 2 & 5 & 2 & 0 & 6 \\
\hline 3 & 6 & 0 & 0 & 4 \\
\hline 4 & 3 & 1 & 0 & 6 \\
\hline 5 & 6 & 0 & 0 & 9 \\
\hline 6 & 6 & 2 & 1 & 4 \\
\hline 7 & 4 & 0 & 0 & 8 \\
\hline 8 & 8 & 0 & 0 & 51 \\
\hline Jumlah (Ekor) & 45 & 5 & 1 & \\
\hline
\end{tabular}

Sumber : Hasil Penelitian

\section{Hasil Tangkapan Berdasarkan Umpan Ikan Bandeng}

Berdasarkan hasil tangkapan dari umpan Ikan Bandeng pada setting hari keenam pada pagi hari mendapatkan hasil tangkapan Ikan Cucut sebanyak 2 ekor, setting sore hari mendapatkan hasil tangkapan Ikan Cucut 3 ekor dan Ikan Meka 1 ekor, pada setting hari kedelapan pagi hari mendapatkan hasil Ikan Cucut 4 ekor, dan setting sore hari mendapatkan hasil tangkapan 2 ekor Ikan Cucut, setting hari kesepuluh mendapatkan hasil tangkapan Ikan Cucut 3 ekor pada pagi hari, untuk setting sore hari mendapatkan hasil tangkapan Ikan Cucut 4 ekor serta 1 ekor Ikan Meka dan 1 Ikan Marlin, setting hari keduabelas pada pagi hari mendapatkan hasil 3 ekor ikan Cucut dan pada setting sore hari didapatkan Ikan Cucut sebanyak 6 ekor, untuk hasilnya dapat dilihat pada Tabel 4. 
Tabel. 4 Jenis dan Hasil Tangkapan Berdasarkan Umpan Ikan Bandeng

\begin{tabular}{|c|c|c|c|c|c|c|c|c|c|}
\hline \multirow{4}{*}{$\begin{array}{l}\text { Jenis } \\
\text { Ikan }\end{array}$} & \multicolumn{8}{|c|}{ Umpan Bandeng (Ekor) } & \multirow{4}{*}{$\begin{array}{c}\text { Jumlah Hasil } \\
\text { Tangkapan } \\
\text { (ekor) }\end{array}$} \\
\hline & \multicolumn{8}{|c|}{ Hari ke } & \\
\hline & \multicolumn{2}{|c|}{6} & \multicolumn{2}{|c|}{8} & \multicolumn{2}{|c|}{10} & \multicolumn{2}{|c|}{12} & \\
\hline & Pagi & Sore & Pagi & Sore & Pagi & Sore & Pagi & Sore & \\
\hline Cucut & 2 & 3 & 4 & 2 & 3 & 4 & 3 & 6 & 27 \\
\hline Meka & 0 & 1 & 0 & 0 & 0 & 1 & 0 & 0 & 2 \\
\hline Marlin & 0 & 0 & 0 & 0 & 0 & 1 & 0 & 0 & 1 \\
\hline $\begin{array}{c}\text { Jumlah } \\
\text { (Ekor) }\end{array}$ & 2 & 4 & 4 & 2 & 3 & 6 & 3 & 6 & 30 \\
\hline
\end{tabular}

Sumber : Hasil Penelitian

Pada penelitian ini jumlah hasil tangkapan dengan umpan Bandeng yaitu ikan Cucut sebanyak 27 ekor dikarenakan ikan Bandeng mempunyai karakteristik dengan tubuh mempunyai sisik yang seperti kaca di dalam air yang membuat ikan Cucut tertarik. Menurut Barata, et al, 2011 menyatakan bahwa Bandeng merupakan jenis umpan yang telah memenuhi persyaratan untuk keberhasilan suatu usaha penangkapan dengan longline. Umpan yang dipakai harus memenuhi beberapa syarat, antara lain mempunyai warna sisik mengkilap di dalam air, tidak cepat busuk, memiliki rangka tulang yang kuat, bentuk badan memanjang dan dalam keadaan segar. Untuk Ikan Meka mendapatkan hasil 2 ekor karena hasil yang didapat pada saat setting sore hari sebab ikan Meka mempunyai sifat yang biasanya aktif pada petang hari, dan Ikan Marlin hanya didapatkan 1 ekor karena pada saat setting dilakukan pada sore hari dimana suhu air di malam hari lebih rendah dibandingkan suhu di pagi hari $31{ }^{\circ} \mathrm{C}$, salah satu adaptasi ikan marlin yang memungkinkan untuk berenang di air dingin tersebut. Menurut Burhanuddin, (2010) bahwa Ikan Marlin dapat hidup dan ditemukan di perairan 41-80 ${ }^{\circ} \mathrm{F}$ (5-27 $\left.{ }^{\circ} \mathrm{C}\right)$.

\section{Hasil Tangkapan Berdasarkan Umpan Ikan Layang}

Berdasarkan hasil tangkapan dari umpan Ikan Layang pada setting hari keenam pada pagi hari mendapatkan hasil tangkapan Ikan Cucut sebanyak 5 ekor, setting sore hari mendapatkan hasil tangkapan Ikan Cucut 2 ekor dan Ikan Meka 1 ekor, pada setting hari kedelapan pagi hari mendapatkan hasil Ikan Cucut 2 ekor, dan setting sore hari mendapatkan hasil tangkapan 1 ekor Ikan Cucut dan Ikan Meka 1 ekor, setting hari kesepuluh mendapatkan hasil tangkapan Ikan Cucut 3 ekor pada pagi hari, untuk setting sore hari mendapatkan hasil tangkapan Ikan Cucut 2 ekor serta 1 ekor Ikan Meka, setting hari keduabelas pada pagi hari mendapatkan hasil 1 ekor ikan Cucut dan pada setting sore hari didapatkan Ikan Cucut sebanyak 2 ekor, untuk hasilnya dapat dilihat pada Tabel 5. 
Tabel. 5 Jenis dan Hasil Tangkapan Berdasarkan Umpan Ikan Layang

\begin{tabular}{|c|c|c|c|c|c|c|c|c|c|}
\hline \multirow{4}{*}{$\begin{array}{l}\text { Jenis } \\
\text { Ikan }\end{array}$} & \multicolumn{8}{|c|}{ Umpan Layang (Ekor) } & \multirow{4}{*}{$\begin{array}{c}\text { Jumlah Hasil } \\
\text { Tangkapan } \\
\text { (Ekor) }\end{array}$} \\
\hline & \multicolumn{8}{|c|}{ Hari ke } & \\
\hline & \multicolumn{2}{|c|}{6} & \multicolumn{2}{|c|}{8} & \multicolumn{2}{|c|}{10} & \multicolumn{2}{|c|}{12} & \\
\hline & Pagi & Sore & Pagi & Sore & Pagi & Sore & Pagi & Sore & \\
\hline Cucut & 5 & 2 & 2 & 1 & 3 & 2 & 1 & 2 & 18 \\
\hline Meka & 0 & 1 & 0 & 1 & 0 & 1 & 0 & 0 & 3 \\
\hline Marlin & 0 & 0 & 0 & 0 & 0 & 0 & 0 & 0 & 0 \\
\hline $\begin{array}{c}\text { Jumlah } \\
\text { (Ekor) }\end{array}$ & 5 & 3 & 2 & 2 & 3 & 3 & 1 & 2 & 21 \\
\hline
\end{tabular}

Sumber : Hasil Penelitian

Hasil tangkapan dengan umpan ikan Layang mendapatkan Ikan Cucut 18 ekor dikarenakan tingkah laku Ikan Cucut yaitu berenang sampai mendekati pantai untuk mencari atau menemukan sumber makanan, sedangkan pada saat penelitian setting dilakukan hampir mendekati pantai, sehingga umpan pada setiap settingnya dapat di makan oleh Ikan Cucut, dan didapatkan hasil tangkapan Ikan Meka 3 ekor karena dilihat dari waktu settingnya, setting dengan hasil Ikan Meka dilakukan pada sore hari dimana sifat dari Ikan Meka yang biasa aktif pada petang hari.

Pengujian pengaruh perbedaan jenis umpan yang berbeda antara Ikan Layang dan Ikan Bandeng terhadap jumlah hasil tangkapan longline dilakukan dengan menggunakan metode statistika, yaitu metode analisis $t$-student sehingga kedua jenis umpan Bandeng dan Layang memiliki peluang yang sama untuk termakan.

1. H0 = Perbedaan jenis umpan yang digunakan tidak memberikan pengaruh terhadap hasil tangkapan secara nyata.

2. $\mathrm{H} 1$ = Perbedaan jenis umpan yang digunakan memberikan pengaruh terhadap hasil tangkapan secara nyata.

Data-data yang digunakan merupakan data jumlah hasil tangkapan yang diperoleh dengan menggunakan kedua jenis umpan selama 8 kali setting. Hal ini terlihat pada Tabel 3, bahwa penggunaan 2 jenis umpan yang berbeda (Bandeng dan Layang) Tidak memberikan pengaruh terhadap jumlah hasil tangkapan.

Data tersebut diolah dengan menggunakan metode analisis $t$-student. Berdasarkan pengolahan data dan perhitungan melalui prosedur metode analisis $t$ student tersebut diperoleh hasil perhitungan yang diplotkan ke dalam Tabel 6. 


\section{Paired Samples Test}

Paired Samples Correlations

\begin{tabular}{|ll|c|c|c|}
\hline & $\mathrm{N}$ & Correlation & Sig. \\
\hline Pair 1 & $\begin{array}{l}\text { Umpan_Bandeng \& } \\
\text { Umpan_Layang }\end{array}$ & 8 & -.209 & .619 \\
\hline
\end{tabular}

Tabel 6. Hasil Perhitungan Analisis Metode $t$-student

\section{Paired Samples Statistics}

\begin{tabular}{|c|c|c|c|c|}
\hline & Mean & $\mathrm{N}$ & Std. Deviation & $\begin{array}{l}\text { Std. Error } \\
\text { Mean }\end{array}$ \\
\hline $\begin{array}{ll}\text { Pair } 1 \text { Umpan_Bandeng } \\
\\
& \text { Umpan_Layang }\end{array}$ & $\begin{array}{l}3.75 \\
2.62\end{array}$ & 8 & $\begin{array}{l}1.581 \\
1.188\end{array}$ & $\begin{array}{l}.559 \\
.420\end{array}$ \\
\hline
\end{tabular}




\begin{tabular}{|c|c|c|c|c|c|c|c|c|}
\hline & \multicolumn{5}{|c|}{ Paired Differences } & \multirow[b]{3}{*}{$\mathrm{t}$} & \multirow[b]{3}{*}{ Df } & \multirow{3}{*}{$\begin{array}{c}\text { Sig. (2) } \\
\text { tailed) }\end{array}$} \\
\hline & \multirow[b]{2}{*}{ Mean } & \multirow{2}{*}{$\begin{array}{c}\text { Std. } \\
\text { Deviation }\end{array}$} & \multirow{2}{*}{$\begin{array}{l}\text { Std. } \\
\text { Error } \\
\text { Mean }\end{array}$} & \multicolumn{2}{|c|}{$\begin{array}{c}95 \% \\
\text { Confidence } \\
\text { Interval of the } \\
\text { Difference }\end{array}$} & & & \\
\hline & & & & Lower & Upper & & & \\
\hline $\begin{aligned} \text { Pair } 1 \text { Umpan } \\
\text { Bandeng - } \\
\text { Umpan } \\
\text { Layang }\end{aligned}$ & 1.125 & 2.167 & .766 & -.687 & 2.937 & 1.468 & 7 & .185 \\
\hline
\end{tabular}

Hubungan korelasi antara umpan Bandeng dan umpan Layang menunjukan hasil -0,209 yaitu hasil antara umpan Bandeng dan Layang bersifat negatif. Dengan demikian hasil tersebut menunjukan antara umpan Bandeng dan umpan Layang tidak ada hubungan secara nyata.

Berdasarkan hasil perhitungan menggunakan metode analisis $t$-student diperoleh nilai $p$-value sebesar 0,185 dan nilai alpha pada tingkat kepercayaan $95 \%=0,05$. Nilai $p$-value lebih besar dari nilai alpha menunjukan kesimpulan penerimaan hipotesa (Terima H0) atau tolak H1. Dengan demikian perbedaan jenis umpan yang digunakan selama penelitian (Ikan Bandeng dan Ikan Layang) tidak memberikan pengaruh perbedaan terhadap jumlah hasil tangkapan secara nyata.

\section{KESIMPULAN DAN SARAN}

Kesimpulan dari hasil penelitian adalah sebagai berikut teknik pengoperasian alat tangkap longline pada KLR. Madidihang 03 yaitu dilakukan dengan tahap persiapan di laut, penurunan alat tangkap (setting), penghanyutan tali pancing (drifting), dan penarikan alat tangkap (hauling). Hasil tangkapan diperoleh dengan umpan Bandeng 30 ekor dan 21 ekor umpan ikan Layang untuk keseluruhan setting yang dilaksanakan. Hasil tangkapan terbanyak pada setting kedelapan dengan jenis umpan bandeng yang menghasilkan tangkapan 8 ekor ikan Cucut di hari keduabelas pada setting sore hari.

Berdasarkan saran dari penelitian dalam penggunaan umpan adalah sebaiknya memfokuskan menggunakan umpan dengan hasil tangkapan, karena dengan penggunaan umpan yang terfokuskan maka akan menghasilkan lebih banyak hasil tangkapan ikan yang dituju. Saat pengoperasian alat tangkap longline sebaiknya melihat atau mengetahui musim penangkapan ikan. 


\section{DAFTAR PUSTAKA}

Barata, Abram, Andi Bahtiar dan Hety Hartaty, 2011. Pengaruh Perbedaan Waktu Setting Rawai Tuna Terhadap Hasil Tangkapan Tuna di Samudera Hindia. Peneliti pada Lokasi Penelitian Perikanan Tuna, Benoa-Bali.

Burhanuddin, A.I.2010. Ikhtiologi: Ikan dan Aspek Kehidupannya. Yayasan Citra Emulsi

Nybakken. (1988). Biologi Laut: Suatu Pendekatan Ekologis. Jakarta: Gramedia

Steel, R. G. D. dan J. H. Torrie. 1991. Prinsip dan Prosedur Statistika. Diterjemahkan oleh Bambang Sumantri. PT. Gramedia Pustaka Utama. Jakarta 